\title{
THE COMPARATIVE STUDY ON STRENGTH CHARACTERISTICS OF LATERITE SOIL AND BLACK COTTON SOIL BY USING RBI GRADE 81 SOIL STABILIZER
}

\author{
Poojeshwari Kotagi ${ }^{1}$, Nagaraj Bacha ${ }^{2}$ \\ ${ }^{I}$ Department of civil engineering, BKIT Bhalki, Bidar, Karnataka \\ ${ }^{2}$ Department of civil engineering, BKIT Bhalki, Bidar, Karnataka
}

\begin{abstract}
Black cotton soil has many complications than the Lateritic soil, as this study deals with the problems of Bidar district soil. District consist unique type of variations, in some parts of district the surface consists the lateritic soil and subsurface consists the black cotton soil up to some extent of depth. Therefore this study deals with the type of blending problem of two soils by using the stabilizer RBI grade 81. The different blending proportions were prepared to know the unconfined strength characteristics of the soil and for all the soil proportions 1\% to 2\% of RBI grade 81 is added and kept curing forl, 3, 5, 7 and 10 day.
\end{abstract}

Keywords: Compaction, OMC, $M D D$

\section{INTRODUCTION}

The earth has many natural sources one of them the most important is soil. The soil has many characteristics and many forms as the place varies soil type and the soil characteristics also vary. Therefore it is much more necessary to study the soil forms and characteristics as being a Geotechnical engineer.

Properties of the Black cotton soil are much complicated. It has the low bearing capacity, high swelling and shrinking characteristics. Based upon the properties of black cotton soil it is unsafe for the construction of any type of structure and also for the sub grade pavements. The soil has the clay mineral Montmorillonite and it varies dark gray to black in color because the compounds present in the soil are iron and titanium.

In the present study Black cotton soil is collected from Bidar district, major part of the district is covered with black cotton soil, the color of the soil is deep in black and the texture of the soil is loam to clay. The infiltration characteristics are poor to moderate.

Lateritic soil is rich in physical and engineering properties as the soil contains iron and aluminum, this soil possesses high strength and it has the less swelling and shrinking characteristics. Lateritic soil has the clay mineral Kaolinite.

For the present study the lateritic soil is collected from Bidar, district. This soil covers the central part of the district. The collected soil is bright red in color and clay to clayey loam in nature. The infiltration characteristic of the soil is moderate to good.
As the study contains two different types of soil as black cotton and lateritic soil, the place of soil Bidar, district has the unique variation or type of soil mixing, in some part the surface layer is of lateritic soil and the sub surface is of black cotton soil up to some depth. This kind of formation of two soil create bond between two layers of soil and that bond is nothing but Blending (mixing of the soil) and to study the blending between the two soil the stabilization technique is adopted. For that blending technique of two soils are stabilized by using the stabilizer RBI grade 81 and it is collected from "Alchemist Technology Ltd. Bangalore" [1].

RBI grade 81 increases the strength of soil gradually after 1 year of treatment. It is in powder form of light grayish color, eco-friendly, when added into the water it will not soluble, after adding it will not change in chemical reaction, odorless, easily available stabilizer and it gives smooth surface after treatment of the soil [2].

A wide range of soil properties can be improved by RBI grade 81 . For silty clays it is much more effective for low geo-mechanical properties. Crystalline growth helps to fill the pore space. By addition minimum dosage of RBI grade 81 the volume stability of the soil increased significantly. After adding the RBI grade 81 into the soil it reacts with the particles and produces as in inter particle matrix that binds the soil particles together into a rigid mass, the binding of the soil particles by both chemical bonds and frictional forces forms the pore volume of created rigid stabilized soil system limit. RBI grade 81 is easy to apply, it forms the dust free surface, hardens fast, permanent and durable [3].

Many researchers are worked on the RBI grade 81 stabilizer with different type of soils and got the positive results. But those studies are conducted only on single soil or the 
comparison between the two soil, are else comparison between the different stabilizers with the RBI grade 81 , such as Anita.K.R. et al [4] studied about the Effect of RBI Grade 81 on different types of sub grade soil and Sushant Bhuyan [6] studied the comparison between the two stabilizer i.e. Stabilization of Blast furnace slag and Fly ash using Lime and RBI Grade 81" (2010) etc. these studies helped the present study to investigate the characteristics of blending of the two soil by using same stabilizer RBI grade 81 as the stabilizer proved in increasing the strength of the soil and it may be gives the much effective results for this study too.

\section{LITERATURE REVIEW}

Raasta (2008) et al [1]; they investigated about laboratory studies on properties of soil treated with proprietary cementitious stabilizer, the study consists of four different type of SC soils and obtained substantial increase in CBR value. After conducting the compressive strength test it is concluded that $1 \%$ to $2 \%$ of stabilizer is effective to improve the properties of clayey soil.

Venugopal.N (2009) et al [2]; they investigated the soil properties by silica fume and RBI grade 81 stabilizer with varying percentage of 1 to 4 . By conducting the triaxial compression test it is concluded that RBI grade 81 is much more effective in improving the strength.

Sushant Bhuyan, (2010) et al [3]; studied about a investigation program on the effect of RBI Grade 81 and lime on industrial waste such as fly ash and blast furnace slag. The objective of this study is to use the industrial waste in place of natural soil for road and highway after increasing its strength. Samples were prepared and RBI grade 81 and lime stabilizers were added. After addition of stabilizer the UCS test was conducted with the respective curing periods. By the test results found that the lime increases more strength than RBI grade 81 .

Satander Kumar, et al (2010) [4]; they investigated the stabilization of soil and aggregate for sub grade and base layer by RBI grade 81 stabilizer. Compressive strength and elastic modulus test were conducted on a sample of mixture of $50 \% 10 \mathrm{~mm}$ down aggregate $+50 \%$ stone dust and RBI grade 81 stabilizer was added with varying percentage of $4 \%, 6 \%$ and $8 \%$ by weight of the sample. After conducting the test for prepared samples it is concluded that strength requirement is satisfied for sub base layer using RBI grade 81.

Vinay et. al. (2011) [5]; studied about the strength properties of loamy soil and clayey soil by stabilizing with RBI grade 81. After stabilizing the samples, flexural strength, durability, permeability, UCS and CBR test were conducted. Test results shown that RBI grade 81 is much more effective in increasing the CBR value and unconfined compressive strength.
For the present study three proportions were prepared with the two different type of soil, first proportion is of $75 \%$ $\mathrm{BC}+25 \% \mathrm{LS}$, second proportion is $50 \% \mathrm{BC}+50 \% \mathrm{LS}$ and third proportion is $25 \%$ B.C $+75 \%$ L.S and after preparation of these proportions the stabilizer RBI grade 81 with varying percentage of $1 \%$ and $2 \%$.

Then the physical and engineering properties tests are conducted such as Atterberg limits, specific gravity, and optimum moisture content, maximum dry density and unconfined compressive strength test for the curing periods of 1,3,5,7 and 10 day and samples were prepared in the mould of constant volume. Ayyanna Habal, (2013) et al [6]; the investigation is done on case study road constructed at Jananbharati campus, Bangalore university, which consists the investigation of existing pavement condition and for the construction purpose Reclaimed Asphalt Pavement (RAP) and RBI grade 81 stabilizer is used for stabilization purpose. By the field studies it is concluded that with increase in the dosage of RBI grade 81the strength of the pavement increases.

K.V.Madhurwar, (2013) et al [7]; they studied about the stabilization of black cotton soil using RBI grade81 and Sodium silicate. The unconfined compressive strength test were carried out with a curing period of 7,14 , and 28 days and addition of stabilizer with a varying percentage of $2 \%$ to $6 \%$ of RBI grade 81 in dry state to the soil and $3 \%$ to $6 \%$ sodium silicate in solution. By the results it is concluded that RBI grade 81 increases the unconfined compressive strength and addition of sodium sulphate indicates that it helps in increasing $\mathrm{pH}$ of soil environment and this results in increase of the strength of the soil.

B.M.Patil, (2013) et al [8]; this study consists the effect of pond ash and RBI grade 81 for clayey soil and grade $3^{\text {rd }}$ material used for base course of flexible pavement. For this study different tests were conducted such as OMC, MDD, UCS, free swell index, and CBR. By the test results it is found that properties of the clayey soil are improved significantly if pond ash is added with RBI grade 81 .

Ahmed Naseem A.K, (2014) et al [9]; the investigation is done on expansive soil collected from Chikaltana village Aurangabad for flexible pavements and stabilized by waste material and natural soil stabilizer with different proportions. And all the properties of the samples were tested and test results shown that strength increases with increase in fly ash and RBI grade 81 . By this study $30 \%$ fly ash and $4 \%$ RBI grade 81 can be used in strengthening the sub grade of black cotton soil in flexible pavements and it is found to be much more economical.

Najia Nouf, (2014) et al [10]; they studied about the effect of RBI grade 81 on black cotton soil which was collected from Nagpur, Maharashtra. And the tests were conducted such as Atterberg limits, Modified Proctor compaction, California Bearing Ratio, Unconfined Compressive Strength, and Consolidation for untreated and treated sample with respective curing periods. After the test results it is 
found that the addition of $1 \%$ to $6 \%$ stabilizer improves the engineering properties of the black cotton soil.

Divya Krishnan.K, (2014) et al [11]; they investigated about the micro analysis of black cotton soil and the soil is stabilized by RBI grade 81 . The two soil samples were prepared E1 and E2 of Highly compressible clay and UCS is increased with the addition of stabilizer and it is found that the increment of strength is higher during the initial stage of curing period. From the SEM micrographs it is found that the changes in microstructure of the treated soil and reduction in pore spaces which explain increase in the strength. The changes in elemental composition of RBI grade 81 treated soil is found favorable, compared to untreated soil as stated in EDS spectra which confirms the chemical reaction between soil and additive. Formation of hydration products is confirmed by SEM and EDS results.

Manisha Gunturi, (2014) et al [12]; the study describes the improvements in the properties of expansive soil when treaded with RBI grade 81 stabilizer. XRF, SEM and UCS were conducted on two samples G1 and G2 of treated and untreated sample. By the test results it is concluded that strength increased with the RBI grade 81 .

Mamta, (2014) et al [13]; in this study they conducted about the investigation of comparison of stabilization of black cotton and laterite soil by RBI grade 81 stabilizer. Test were conducted California bearing ratio test and unconfined compressive strength test and result were found that strength increases with increase in percentage RBI grade 81 stabilizer and CBR value increases with increasing in curing periods.

\section{MATERIALS AND METHODOLOGY}

\subsection{Materials}

In this study consists the three materials i.e. Black cotton soil, Lateritic soil and RBI grade 81 .

\subsubsection{Black Cotton Soil}

Soil was collected from Bidar, district from an open excavation, at a depth of $1 \mathrm{~m}$ to $1.5 \mathrm{~m}$ below the ground surface. The soil is deep in black colour and texture is loam to clay, infiltration characteristics are poor to moderate.(The physical property of the soil is tabulated in table 1).

\subsubsection{Lateritic Soil}

Soil was collected from Bidar, district from an open excavation, at a depth of $1 \mathrm{~m}$ to $1.5 \mathrm{~m}$ below the natural ground surface. The collected soil is brick red in colour and infiltration characteristics of the soil are moderate to good. (The physical property of the soil is tabulated in table 1).

\subsubsection{RBI Grade 81}

RBI Grade 81 is a hydration activated powder based stabilizer which reacts with soil. Material for the testing work is received from M/S Alchemist Technology Limited,
Bangalore, India. Chemical composition and properties of RBI Grade 81 are tabulated in table 2 (provided by the supplier);

Properties of RBI grade 81:

$>$ Construction Time and Cost reduction.

$>$ Drastically increases the strength.

$>$ Treated layers are water resistant.

$>$ Reduces thickness, use of transport, and earthmoving machinery substantially.

> Longer Durability which reduces Maintenance.

$>$ Longer Durability which reduces Maintenance.

Table 1: Physical properties of soil

\begin{tabular}{|l|l|l|l|}
\hline SL.N0 & Properties & $\begin{array}{l}\text { Lateritic } \\
\text { soil }\end{array}$ & B.C soil \\
\hline 1 & Specific gravity & 2.64 & 2.3 \\
\hline 2 & Consistency & & \\
& limit & $34.5 \%$ & \\
& Liquid limit & $8.2 \%$ & $66 \%$ \\
& Shrinkage limit & $18.65 \%$ & $13.5 \%$ \\
& Plastic limit & $15.83 \%$ & $50.4 \%$ \\
& Plasticity index & & $15.32 \%$ \\
\hline 4 & IS soil & $\mathrm{MH}$ & $\mathrm{CH}$ \\
\hline 5 & classification & & \\
\hline 6 & ODD (glcc) & $1.8 \mathrm{glcc}$ & 1.65 \\
\hline
\end{tabular}

\subsection{Methodology}

\subsubsection{Sample Preparation}

Three different proportions of soil samples were prepared as $75 \%$ L.S $+25 \%$ B.C, $50 \%$ B.C+50\% L.S and $75 \%$ B.C+ $25 \%$ L.S. after preparing the soil proportions, untreated UCS specimens were prepared for each proportions and kept in air tight desiccators for the curing periods of $1,3,5,7$, and 10 day, test was conducted for the untreated specimens with the respective curing periods. For the treated samples same soil proportions were prepared and added RBI grade 81 with varying percentage of $1 \%$ and $2 \%$ and each percentage consists of one UCS specimens for all the three different proportions of soil samples and prepared samples were kept in air tight desiccators and test was conducted with same curing periods of $1,3,5,7$ and 10day.

\section{RESULTS AND DISCUSSIONS}

\subsection{Unconfined Compressive Strength Test Results}

The effect of unconfined compression strength was tested with the number of days of curing period as 1,3,5,7 and 10 for different blending proportions of the treated and untreated soil samples. Correlation chart for unconfined compressive strength test for the curing period of $1,3,5,7$ and 10 day are shown from chart 4.1 to chart 4.7 . 


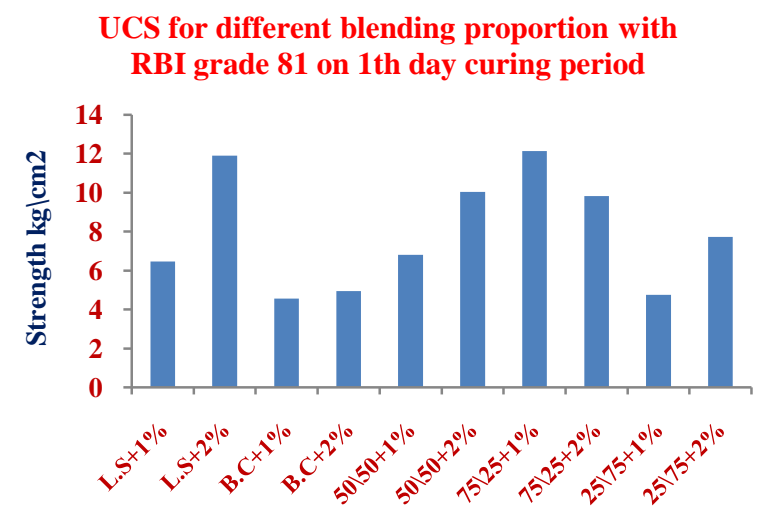

Different proportions

Chart 4.1; shows the correlation for UCS of all blending proportion treated with RBI grade 81 on $1^{\text {st }}$ day curing period.

Chart 4.1 shows correlation of $1^{\text {st }}$ day curing period for UCS strength, found that $2 \% \mathrm{RBI}$ grade 81 is maximum in increasing the UCS strength for all the blending proportion of the soil.

UCS for different blending proportion with RBI grade 81 on 3rd day curing period

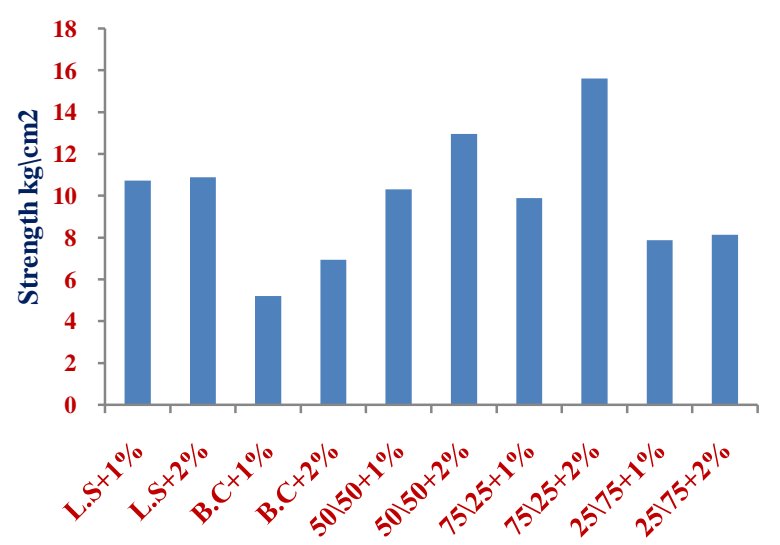

Different proportions

Chart 4.2; shows the correlation for UCS of all blending proportion treated with RBI grade 81 on $1^{\text {st }}$ day curing period.

Chart 4.2 shows correlation of $3^{\text {rd }}$ day curing period for UCS strength, found that $2 \%$ RBI grade 81 is maximum in increasing the UCS strength for all the blending proportion of the soil.

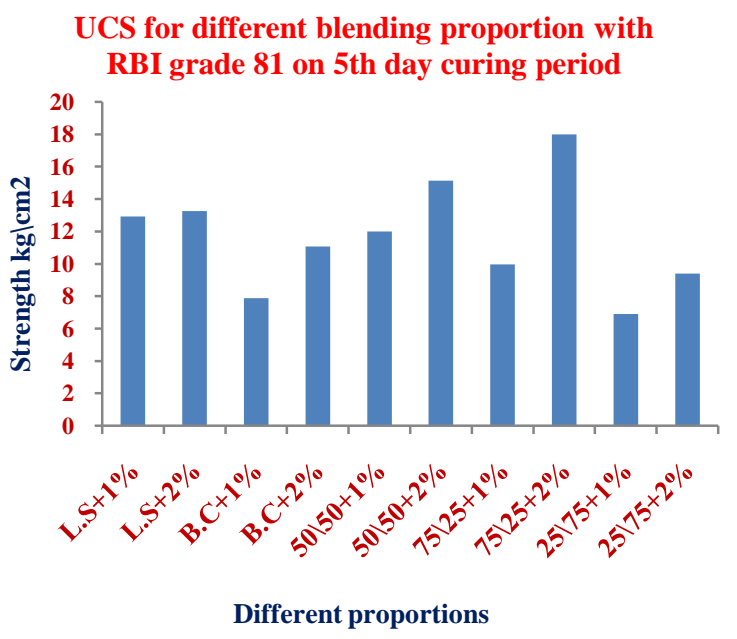

Chart 4.3; shows the correlation for UCS of all blending proportion treated with RBI grade 81 on $1^{\text {st }}$ day curing period.

Chart 4.3; shows correlation of $5^{\text {th }}$ day curing period for UCS strength, found that $2 \% \mathrm{RBI}$ grade 81 is maximum in increasing the UCS strength for all the blending proportion of the soil.

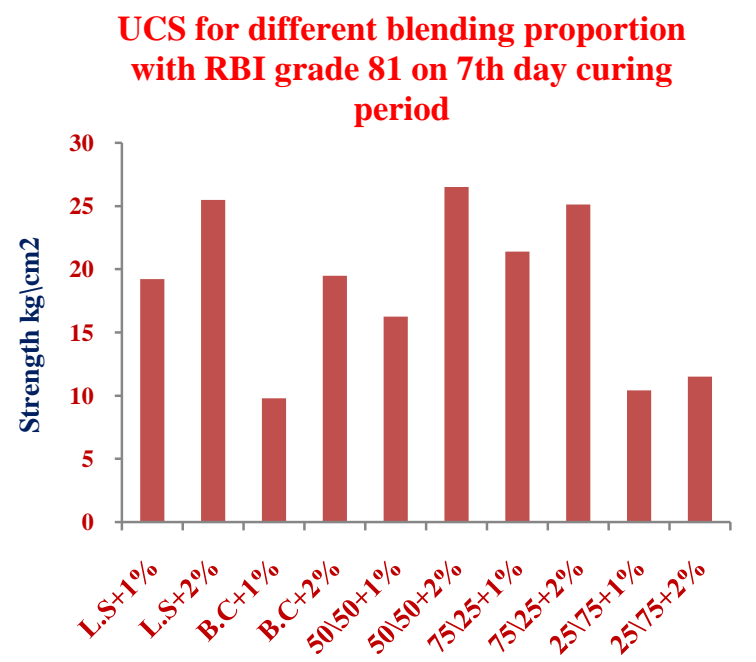

Different proportions

Chart 4.4; shows the correlation for UCS of all blending proportion treated with RBI grade 81 on $1^{\text {st }}$ day curing period.

Chart 4.4; shows correlation of $7^{\text {th }}$ day curing period is optimum for UCS strength, found that $2 \%$ RBI grade 81 is maximum in increasing the UCS strength for all the blending proportion of the soil. 
UCS for different blending proportion with RBI grade 81 on 10th day curing period

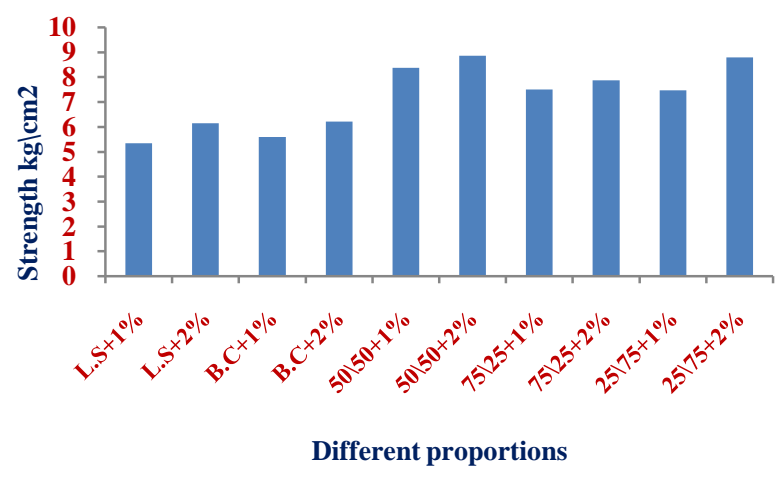

Chart 4.5; shows the correlation for UCS of all blending proportion treated with RBI grade 81 on $10^{\text {th }}$ day curing period.

Chart 4.5; shows correlation of $10^{\text {th }}$ day curing period is for UCS strength; found that after $10^{\text {th }}$ day the $1 \%$ to $2 \%$ RBI grade 81 is minimum in increasing the UCS strength compare to the other curing periods for all the blending proportion of the soil.

\section{CONCLUSION}

Earlier studied were carried out mainly about index properties as liquid limit, plastic limit of higher activity clays when exposes to various contaminants. However, very limited study focused on strengthening of the soil having different problems. Hence, in this study extensive experimental work was done to understand the strength characteristics of blending technique of two soils for different proportions of soil samples such as $75 \%$ L.S $+25 \%$ B.C, $50 \%$ L.S $+50 \%$ B.C and $25 \%$ L.S $+75 \%$ B.C.

From the present study following conclusions may be drawn;

1. Unconfined compressive increases with the increase in curing period and increase in percentage of RBI grade 81 , in this study found that $50 \%$ L.S $+50 \%$ B.C with $2 \%$ RBI grade 81 on $7^{\text {th }}$ day of curing has maximum strength.

2. This study concluded that weak soil can be strengthen by blending the soil with another soil having rich properties, and this blending two soil can stabilized by the stabilizer RBI grade 81 .

This investigation was conducted to study the effect of blending technique of soil and effect of RBI grade 81 on the blending proportion of $75 \%$ L.S $+25 \%$ B.C, $50 \%$ L.S $+50 \%$ B.C and $25 \%$ L.S $+75 \%$ B.C. The soil was tested for unconfined compressive strength. The addition of RBI grade 81 with varying percentage of $1 \%$ to $2 \%$. Unconfined compressive strength for different blending proportion of the soil sample with $1,3,5,7$ and 10 day curing period increases with increase in percentage of RBI grade 81 stabilizers. $50 \%$ L.S $+50 \%$ B.C stabilized with $2 \%$ RBI grade 81 gives the maximum strength on the $7^{\text {th }}$ day of curing.

\section{REFERENCES}

[1]. RAASTA Center for Road Technology, Bangalore. Laboratory studies on properties of soils treated with RBI 81 stabilizer, Report submitted to Legend Surface Developers Pvt. Ltd, New Delhi.

[2]. Venu Gopal.N; (2009), "Study Of Soil Properties With Silica fume As Stabilizer And Comparing The same With Rbi-81 And Cost Estimation" Post Graduate Diploma Thesis, Visvesvaraya Technological University, Belgaum.

[3]. Sushant Bhuyan, Stabilization of Blast furnace slag and Fly ash using Lime and RBI Grade 81" (2010) Project report BE (Civil Engineering) National institute of Technology Rourkela.

[4]. Satander Kumar and Anukul Saxena., "Soil and Aggregate Stabilization for Sustainable Pavement" NBM\&CW, December 2010.

[5]. Vinay, et.al (2011), Strength properties of soil treated with stabilizers, Project report - RAASTA- Centre for road technology.

[6]. Ayyanna Habal, Kavya P, Amarnath M S "Performance evaluation of cold recycling experimental stretch constructed with rbi-grade-81 at Bangalore university", ICRICE Conference Issue | Nov-2013.

[7]. K. V. Madurwar, P. P. Dahale, A. N .Burile (2013), Comparative Study of Black Cotton Soil Stabilization with RBI Grade 81 and Sodium Silicate, International Journal of Innovative Research in Science, Engineering and Technology.

[8]. B.M.Ptil, " Effect of Pond Ash and RBI Grade 81 on Properties of Subgrade Soil and Base Course of Flexible Pavement", World Academy of Science, Engineering and Technology International Journal of Civil, Structural, Construction and Architectural Engineering Vol:7, No:12, 2013.

[9]. Ahmed. Naseem A.K, "Effect of Fly ash and RBI Grade 81 on Black Cotton soil as a sub grade for Flexible Pavements", World Academy of Science, Engineering and Technology International Journal of Civil, Structural, Construction and Architectural Engineering Vol:7, No:12, 2013.

[10]. Najia Nauf, "Effect of RBI grade 81 on Black cotton soil", International Journal of Recent Development in Engineering and Technology Website: www.ijrdet.com (ISSN 2347 - 6435 (Online)) Volume No., Issue No., Month 2014).

[11]. Divya Krishnan, "Experimental study on strength properties of problematic soils with RBI - 81 stabilizer", International journal of civil and structural engineering Volume 4, No 3, 2014.

[12]. Manisha Gunturi, "study on strength characteristics of soil using soil stabiliser RBI - 81" Volume: 03 Issue: 04 | Apr-2014.

[13]. Mamta, "Using RBI grade 81 a comparative study of black cotton soil and lateritic soil", Volume: 03 Special Issue: 03 | May-2014. 